\title{
Locura sublime. Indicios de vacuidad y espiritualidad crítica en Stultitiae Laus de Erasmo
}

\section{Sublime Craziness. Traces of Nihilism and Critical Spirituality in Erasmus' Stultitiae Laus}

\author{
Héctor Sevilla Godínez \\ Centro Universitario de los Valles, Universidad de Guadalajara, México \\ hectorsevilla@hotmail.com \\ Recibido: 13/04/2016 • Aceptado: 12/09/2016
}

\begin{abstract}
Resumen
El artículo indaga si la experiencia de la vacuidad está presente en el Elogio a la locura (Stultitiae Laus) de Erasmo de Rotterdam; tal vivencia, derivada del rechazo a las posturas convencionales de la sociedad y la denuncia del inapropiado testimonio de religiosos y clérigos, sustenta la antesala de un posicionamiento individual que dirige a la opción por la locura cínica o la locura mística. Al abordar la intención erasmiana implícita en el contenido de su obra, se realiza un aporte sobre la esencia de la locura aludida en ella. Asimismo, se señala a la ironía como herramienta literaria y se advierte la presencia de una espiritualidad nihilista que es producto de la opción temeraria por la insensatez sublime de la mística. El enfoque metodológico directriz será la hermenéutica filosófica centrada en los textos.
\end{abstract}

Palabras clave: criticidad, Erasmo de Rotterdam, espiritualidad, locura, vacuidad.

\section{Abstract}

The article inquires into the presence of an experience of vacuity in Erasmus of Rotterdam's The Praise of Folly (Stultitiae Laus); such an experience is derived from the rejection of society's conventional postures and the denouncement of the inappropriate religious and clerical testimony, sustains the prelude of an individual positioning that directs the option through cynical insanity or mystical craziness. Upon boarding the erasmian intention implied in the content of his works, a contribution is undergone about the 
essence of craziness that is alluded in it. Likewise, irony is pointed out as a literary tool, also the presence of a nihilistic spirituality, which is a product of the fearless option for the sublime folly of mysticism, is forewarned. The methodological approach will be the philosophical hermeneutic focused on the texts.

Keywords: Craziness, Criticism, Emptiness, Erasmus, Spirituality. 
Erasmo y su pasión por las letras

Erasmo nació en Rotterdam durante el año 1466. Fue hijo ilegítimo de un sacerdote y su empleada doméstica. No obstante, según Halkin, logró ser considerado "uno de los tres gigantes de la historia espiritual de su generación, con Martín Lutero y san Ignacio” (2012: 10). Desde pequeño, fue formado con los Hermanos de la Vida Común, una congregación nacida a finales del siglo XIV, caracterizada por el gusto de la libertad y del estudio, ambas cualidades testimoniadas en forma clara y evidente por Erasmo durante toda su vida.

Es claro que la independencia de espíritu de Erasmo no encajaba con la vida de un monje tradicional; no se contentó con las formas establecidas de lo que era la espiritualidad y trató de varias formas denunciar, muchas veces por medio de su arte literario, lo que él consideraba incongruencias. Es muy probable que haya vivido avergonzado por su nacimiento fuera de la regla monástica de su padre, pero sería muy osado sugerir que su trabajo es un esfuerzo por compensar el pecado paterno. De hecho, no hay indicios de que así sea, a menos que se desee forzar la explicación de su legado con parámetros psicoanalíticos.

Es significativo que su aprecio por las letras, su interés en promover el desarrollo de la vida espiritual de las personas y su refinado arte didáctico por medio de sus textos le haya ganado el título de "príncipe de los humanistas" (Halkin, 2012: 13) o el más elaborado de "maestro y príncipe de los humanistas cristianos" (Rodríguez, 2013: 13). Es posible que se le conozca más en el ámbito del humanismo que del cristianismo, y aunque Erasmo se mantuvo firme en su militancia a la Iglesia Católica, sus escritos pueden ser aprovechables para cualquiera que no comparta ese credo. A pesar de todo, "Erasmo sigue siendo más célebre que conocido" (Halkin, 2012: 9).

Antes de que aconteciera la reforma de la Iglesia y la intervención de Lutero, con quien está de acuerdo en muchas cosas, Erasmo 
ya había señalado algunos de los errores de los individuos que conformaban la Iglesia en su tiempo. De hecho, el pensador de Rotterdam ya había sugerido una serie de cambios en la manera de entender la religión. A su vez, a los teólogos les recomendó continuamente el amor a las letras para lograr realizar una exégesis idónea de las escrituras.

De Erasmo debe señalarse la libertad y el ánimo inquebrantable por cumplir lo que consideró que era su misión. Sobre la motivación que le invitaba a escribir sus obras afirmó categóricamente: "Mi único propósito en la publicación de todos mis libros ha sido siempre hacer algo útil con mi trabajo. Y caso de no conseguirlo, por lo menos no dañar a nadie" (2013: 181). Ese propósito se mantuvo a pesar de recibir propuestas significativas para mejorar su condición económica y su confort. Una de tales ocasiones fue cuando se le ofreció un obispado en Sicilia; la expresión de Erasmo, contenida en una de sus cartas relativas al tema, muestra su afán de independencia: "No cambiaría mi libertad por el más espléndido de los obispados" (1958: 357). De hecho, uno de los señalamientos más claros de Erasmo, respecto a la libertad de expresión, es que ésta puede disminuir cuando se forma parte de instituciones educativas o religiosas que tienden a ser autoritarias.

Entre las características centrales de la erudición de Erasmo se encuentra su interés por ir a las fuentes clásicas. Es, en ese sentido, un innovador en el enfoque; no cae en el romance de lo novedoso o en la idea pueril de que lo antiguo debe despreciarse sino que, contrariamente, invita a la consideración de la sabiduría clásica y promueve su adaptación a los contextos de su tiempo. Es por esto que, según Halkin, puede considerarse al autor de los Adagios como un "revolucionario del pensamiento, precisamente en el hecho de que vuelve a las fuentes" (2012: 14). El acercamiento a las letras en Erasmo está sostenido en la idea de que "la historia y la sabiduría antigua pueden servir de modelo y ejemplo al hombre moderno" (Rodríguez, 2013: 13). Precisamente, regresar a la sabiduría previa constituye, claramente, uno de los motores de este texto, a saber: coadyuvar a que el pensamiento de Erasmo, hoy considerado antiguo, sea urgentemente resignificado en todas sus posibilidades actuales. 
Erasmo tenía agrado en la interlocución con pensadores que le eran contemporáneos y son memorables sus correspondencias con Roger Servais, Pierre Gilles, Jaques Batt o Tomás Moro; no obstante, mucho de su interés residía en el «diálogo» con autores que escribieron varios siglos antes que él, en cuyos textos encontró siempre resonancias y motivación. Uno de sus autores de cabecera fue Luciano de Samosata. A pesar de seguirlos y de tomar algunos de sus enfoques, no fue un seguidor sumiso. De tal menara, "ama a los autores antiguos, los conoce, los cultiva: no les presta un valor absoluto. Se adhirió a su escuela para no confundirse con ellos, sino para definirse en relación a ellos" (Halkin, 2012: 174).

Es evidente que, a pesar de lo implacable de su pluma para señalar abiertamente los errores de obispos y autoridades clericales, Erasmo mantuvo una profunda religiosidad; sin embargo, si bien "la doctrina de la filosofía de Cristo inspira la obra entera de Erasmo, la domina y, en cierta medida, la determina" (Halkin, 2012: 174), esto no sugiere que sus letras sean dirigidas en forma exclusiva a los cristianos o que su acuosidad sólo refresque la sed de los que conforman su comunidad teísta. El honesto y ávido buscador contemporáneo puede también recurrir a la profundidad del filólogo holandés para encontrar respuestas. En su momento, Erasmo reconoció, por ejemplo, que a pesar de que los judíos no aceptan la enseñanza de Cristo, según lo refiere él mismo (2013: 216), el libro de los profetas y los salmos escritos en su lengua tienen un esencial e innegable significado para los cristianos. Hasta cierto punto, puede reconocerse en esta actitud un primer esbozo de ecumenismo.

Entre las pasiones de Erasmo no se encontraba el dinero, al cual consideró un generador del tipo de ansiedad que es la causa de todos los males sociales. A tal ansiedad renunció durante su vida y fue hasta sus últimos años que, tras el éxito de sus obras, logró cierta solvencia económica. Asimismo, es claro el rechazo permanente que tuvo hacia la guerra y no se encuentra ningún rasgo que la proponga en el contenido de sus obras.

La pasión de Erasmo fue escribir, de tal modo que se entregó a sus letras, mucho más que a su ejercicio docente en el aula. En ese sentido, "su vocación verdadera es una vocación de hombre de 
estudios que se entrega a sus investigaciones, a sus publicaciones futuras" (Halkin, 2012: 27). Además, intercambió comunicación con varios de sus colegas, de tal modo que se conocen más de tres mil cartas, las cuales son evidencia de lo que afirmó en una de ellas: "La pasión de escribir crece escribiendo" (1958: 104). Su maestría epistolar la ofreció en la obra Del arte de escribir una carta, en la cual manifiesta el poder de este tipo de comunicación.

Entre sus escritos también pueden encontrarse los Coloquios, cuya intención era expositiva y didáctica; tales compendios lograron ser "uno de los más grandes éxitos de librería del siglo XVI" (Halkin, 2012: 109). Sobresalen también los Adagios, título genérico que une los textos llamados "Colección” y "Millares", los cuales fueron enriquecidos desde el año 1500 hasta 1536 y completaron 4151 adagios con comentarios históricos y filológicos. Según Fantazzi el compendio es considerado "una despensa repleta de la sabiduría de la Antigüedad, enriquecida y engalanada por los comentarios eruditos de Erasmo" (2008: 11).

A pesar de su gran producción, propia de un compromiso sostenido y disciplinado, Erasmo mantenía una visión autocrítica de sí mismo; en una de sus cartas manifiesta lo siguiente: "Hace mucho tiempo que prometo grandes cosas y que me retraso por mi pereza, por alguna suerte contraria o por la enfermedad" (1958: 320). Asimismo, la exigencia sobre sí también se convertía en benevolencia cuando enfrentaba las críticas que sus obras recibían; en el prólogo de su Elogio de la Locura le comenta a Tomás Moro: "La gente puede juzgarme como quiera. Pero, si mi amor propio no me engaña, mi elogio de la estulticia no ha sido tan fatuo" (2013: 38-39). A la vez, Erasmo sabía que la obra referida ofendería a algunos de los lectores, sobre todo a los eclesiásticos, por lo que sentencia de forma contundente: "Quien se ofende por haber sido herido está poniendo de manifiesto su conciencia de culpable o al menos sus temores" (2013: 39).

No obstante el compromiso de Erasmo con su oficio de escritor y denunciante, existe también la visión contraria en relación a su entrega social. En la opinión de Perez el filósofo de Rotterdam no tuvo un compromiso a la altura de Vives o de Moro; de tal modo, el 
autor referido considera que la postura de Erasmo era ambigua, en función de que "quiere preservar a toda costa su libertad y por eso se niega a comprometerse a fondo en cualquier causa" (2015: 12). Sin embargo, la lucha de Erasmo estaba puesta en sus escritos, sabía que su obra le requería bastantes años y que no podía poner en riesgo el tiempo necesario para realizarla.

El hombre que odiaba la guerra supo generar una confrontación constante por medio de su arma más preciada: su pluma; esta herramienta, en sus manos, pudo ser útil en virtud de su pasión por las letras, condición ineludible que condiciona el valor de lo escrito. De tal modo, no cabe duda de que Erasmo puede ser referido como "el último de los grandes escritores latinos" (Halkin, 2012: 116).

La intención de elogiar a la locura

La más famosa de las obras de Erasmo tiene el nombre griego de Morías Encomion, o Encomio de la moría. A su vez, el texto en latín lleva por título Stultitiae Laus, el cual ha sido traducido como Elogio de la Locura. El término «moría» puede ser también entendido como necedad, tontería, insensatez, estulticia o locura. Erasmo no alude a la locura que es propia de un estado mental trastornado o que viene acompañada de una alteración psíquica grave, a lo cual le convendría más la expresión latina insania, la cual se asocia a falta de cordura e incapacidad fisiológica para lograrla; por el contrario, la locura en la que se centra Erasmo está vinculada a la insensatez.

El Elogio es una obra con alto contenido satírico en la que el autor refleja el cúmulo de experiencias que ha tenido como producto de sus viajes, relaciones y estudios. Podría decirse, junto con Moya que tal libro "constituye una recapitulación de cuanto el autor había leído y asimilado en el curso de, aproximadamente, cuarenta años” (2008: 219). Hasta cierto punto es una especie de espejo de la sociedad en la que vivió, un texto que mantiene su vigencia en la actualidad por sus coincidencias con nuestra época. La Locura es, en este libro, un personaje central, protagonista y guía en el periplo reflexivo al que invita el texto. El mundo es representado como un teatro en el que 
las personas actúan y son a la vez espectadores de las actuaciones de los demás. Se cuestiona la veracidad de los discursos, la gentileza de las relaciones, la profundidad de las devociones, la intelectualidad de los religiosos, la congruencia de los maridos y esposas, la moral de los dirigentes y reyes, la valía de los libros y las obras intelectuales, el contenido del arte popular y varios tópicos más.

Incluso aquellos que están fuera del círculo de Erasmo, principalmente los generadores de guerras y encuentros belicosos, son referidos por la Locura en sus señalamientos; de tal modo, "no pudiendo detener a los responsables de la violencia, los alcanza con la única arma que le queda, la ironía" (Halkin, 2012: 133). En ese sentido, conviene recuperar y repensar el texto erasmiano en la vertiginosa situación del mundo contemporáneo, tan golpeado por la violencia y los enfrentamientos sociales. La intención de sus páginas es evidentemente didáctica y representa una profunda y accesible crítica social. Por ello, coincido con Rodríguez cuando afirma que "rescatarlo y hacerlo nuestro es una tarea urgente" (2013: 10).

Erasmo es sobradamente capaz de distinguir entre las formas y el fondo; es por ello que "condena los abusos, no las instituciones; el formalismo, no la piedad; las devociones mecánicas, no los sacramentos y la liturgia” (Halkin, 2012: 151). Cuando Martín Dorp, humanista y teólogo que ocupó el cargo de rector de la Universidad de Lovaina, alude a diversas críticas propiciadas por la obra erasmiana, el autor de la Stultitiae Laus manifestó que su intención no había sido contrarrestar al cristianismo ni acusar directamente a alguien en particular. Por ello asegura: "No querría haber escrito nada, incluso en broma, que pudiera ofender en ningún sentido la piedad cristiana" (Erasmo, 2013: 207); no obstante, sabe distinguir entre ofender y causar molestia, porque ubica que provocar una molestia en el lector puede conducirlo a la reparación de su error. De tal modo, no es complejo que quien se sienta identificado experimente una molestia que podría llevar a cierta actitud consciente.

El pensador de Rotterdam se inquietaba ante la actitud defensiva de algunos lectores quienes, lejanamente de promover su propio cambio al sentirse aludidos, señalaron la osadía erasmiana y le incluyeron entre las personas no gratas. Incluso, muchos de los seguidores 
de Erasmo resultaron igualmente señalados y tristemente olvidados. Esto explica la petición que realiza Erasmo a Dorp: "Sólo pido que alguien quiera entender lo que he escrito, alguien honesto y abierto, que esté dispuesto a comprender sin prejuicios que le lleven a una falsa interpretación" (2013: 207).

El anhelo referido no obtuvo una respuesta satisfactoria. El Elogio de la Locura fue una obra vista "como una provocación y un escándalo para los hombres de su tiempo” (Rodríguez, 2013: 21). Es evidente que, a pesar de las disculpas de Erasmo, el libro no contiene un conjunto de alabanzas a las autoridades clericales, sino que es "un ataque frontal basado en la ironía, en la risa, la crítica y el sarcasmo a la sociedad y a la Iglesia de su época” (Rodríguez, 2013: 21). Obviamente, la crítica fue a los religiosos y no a la religión, a los miembros de la Iglesia y no a la Iglesia como tal, a los cristianos pero no a Cristo. A final de cuentas, la esencia de un libro es propiciar un cambio en el lector, no permitirle mantener una actitud irreflexiva ante los temas más fundamentales de la existencia. En ese tenor, la obra de Erasmo cumple con su cometido, a pesar de acarrear para el autor una serie de persecuciones molestas y ruines, las cuales duraron hasta el final de su vida.

Al igual que Eckhart, criticado por los mismos dominicos de su época, o en resonancia con el señalamiento que sufrió Spinoza por algunos miembros de la comunidad judía en su tiempo, a Erasmo, en medio de ambos, le correspondió, históricamente, soportar el yugo de la coerción eclesiástica; tal como advierten De Paz, Padrón y Salas (2008), entre los principales antierasmistas puede mencionarse a Sancho Carranza, de la Universidad de Alcalá, y Diego López de Zúñiga, quien arremetió violentamente contra la traducción del Nuevo Testamento realizada por Erasmo. Persiste hasta hoy sin ser explicable, al menos con razones que no sean viscerales, el hecho de que Erasmo no haya sido incluido entre los doctores y maestros de la Iglesia; de cualquier manera, considerando la vastedad y calidad de su obra, puede concluirse que no es algo que su legado necesite.

Erasmo no consideró importante la fama que le atrajo el libro que nos ocupa. En su reveladora respuesta a Dorp manifiesta: "Quiero ser franco y decirte que casi me arrepiento de haber escrito la 
Moría. Ese librito me ha dado fama, o si lo prefieres cierto renombre. Pero yo no suelo mezclar la gloria con el odio, y bien sabe el cielo que lo que el pueblo llama fama no es otra cosa que una palabra vana y un legado pagano" (Erasmo, 2013: 181). Cabe decir que cuando la Moría apareció en 1511, el autor ya era considerado una celebridad. No obstante, la declamación que la Locura realiza en el libro de Erasmo sí representa su obra más conocida y leída hasta nuestros días; de tal manera, el personaje de la Locura acertó al decir que la ficción y las obras que promueven la risa y el espacio lúdico "son las que exaltan a esa bestia potente e inmensa que es el pueblo" (2013: 75). En todo caso, cuando la misma Stultia parlante refiere que "tanto el mundo antiguo como el moderno forman un cortejo de adoradores de la stultitia" (2013: 24), posiblemente olvidó incluir al que en ese entonces constituía el mundo futuro y que es hoy lo que conocemos.

Comparado con los 36 años que Erasmo dedicó a sus Adagios o el constante esfuerzo que le representó la edición bilingüe (griego y latín) del Nuevo Testamento, incluidas las modificaciones y añadiduras que realizó en cada una de sus cinco ediciones desde 1516 hasta 1535, el Elogio de la Locura, escrito en una semana de 1509 mientras Erasmo descansaba en la casa de Tomás Moro, resulta, lógicamente, una obra de menor rigor. Aun así, puede resultar compleja para el lector contemporáneo que no esté habituado a las referencias literarias clásicas y al contexto cultural que constantemente refiere el nacido en Rotterdam. Es evidente que no puede agotarse la producción de Erasmo, ni el conocimiento de su vasta obra, con las palabras que pone en la Locura. Por ello, "hacer consistir a todo Erasmo en la Moría es lo mismo que hacer consistir una vida laboriosa en la semana de vacaciones que le bastó para escribir esta obrita de pasatiempo" (Bataillon, 1966: 73). No obstante, el Elogio a la Locura ha sido considerado, según Oelker (2005: 12), como una de las tres obras claves del Renacimiento, junto con la Utopía de Moro y la Abadía de Thélème en el Gargantúa de Rabelais; en cada una de tales se encuentra un pensamiento rebelde y propositivo mediado de la risa y la ironía.

Finalmente, cabe decir que el Elogio de la Locura constituye una versión sintética de algunos aspectos del pensamiento de Erasmo; tal como él mismo refiere (2013: 184): “En la Moría expresé las mismas 
ideas que en el Enchiridion, pero en broma”. Es oportuno mencionar que el movimiento erasmista español encontró en el Enchiridion el fundamento de su ideología. De tal manera, en la Moría, obra que tiene tantos títulos posibles como las caras que manifiesta la locura, se encuentra un esbozo de espiritualidad crítica y varios indicios de pensamiento sobre la vacuidad que sustentan e impulsan el pensamiento filosófico de Erasmo; ambos elementos están matizados en una visión dual de la locura, que al mismo tiempo posee la cualidad del cinismo y está dotada de una sutil esencia sublime. Tal caracterización será detallada en las páginas que continúan.

\section{La esencia de la locura}

Lejos de ser una maldición o una deshonra, la locura que presenta Erasmo se presenta como la que mueve al mundo. Desde luego, en un terreno distinto al propio de la psicopatología, la locura que elogia Erasmo es la de los que rebasan aquello que algunos, pero nunca el vulgo, ha entendido como el sentido común. Es evidente que Erasmo era consciente que "al espíritu humano le es más connatural y accesible la ficción que la verdad” (Moya, 2008: 222). Son distinguibles dos tipos de locura en la especificación conductual que describe, con sobrados ejemplos, el pensador de Rotterdam. Se abordarán enseguida algunos de los elementos centrales que distinguen esencialmente a esta locura digna de consideración.

1) La locura es necesaria, de acuerdo con la alabanza que ella misma como protagonista elabora para sí misma en la obra erasmiana, para disfrutar la vida; esto no es asunto opcional sino que cabe la sentencia de que "sin la insensatez nada hay agradable en la vida" (Erasmo, 2013: 158). Es por esto que la locura es capaz de afirmar sobre sí misma que es la única que, a su voluntad, hace reír a los dioses y a los hombres. Cierta locura es un requisito fundamental para el disfrute. En otras de sus obras, Erasmo alude a Epicuro e incluso le rinde homenaje "por haber considerado la paz del alma como soberano bien" (Halkin, 2012: 167). De tal modo, la locura es una mediación insustituible para cierto gozo de la vida, para el disfrute, el placer y la aventura. 
2) Cuando este ingrediente de locura es ausente se privilegia la sensatez, la ecuanimidad y la formalidad, cuestiones, todas ellas, que se manifiestan alejadas del disfrute. Erasmo alude claramente, en una obvia ironía y posible descripción de sí, a una categoría de hombres que tratan de escapar del lazo con la locura; concretamente, refiere que "este tipo de hombres entregados día y noche a la sabiduría son desdichadísimos en todo, en especial a la hora de engendrar hijos" (2013: 73). Bajo ese tenor se entiende que "Dios prohibió al hombre comer del árbol de la sabiduría, como si el conocimiento fuera veneno para la felicidad" (2013: 169).

3) Al no contar con las habilidades sociales que le convertirían en un tipo deseable o aplaudido, el sabio que describe Erasmo, o el que pretende serlo de acuerdo con la convención tradicional de sabiduría, se vuelve un tipo que es difícil de frecuentar, complejo y testarudo para las relaciones humanas. Tanto está fuera de la lógica mundana quien así persiste que no podrá obtener fama ni gloria. De tal modo, el personaje de la locura dicta una sentencia tremebunda: "Invita a comer a un sabio y aburrirá al más pintado con su lúgubre silencio o con sus preguntas quisquillosas. Llévalo a una fiesta, y te parecerá un camello dando vueltas. Lánzalo a un espectáculo público y su misma cara desvanecerá la alegría del pueblo" (2013: 73). No precisar de un poco de locura genera aislamiento y desazón; por el contrario, la locura acerca a las personas y su insensatez les permite convivir en el mutuo elogio, en la negación de los descontentos, en la elección de la simpleza y el desprecio por la complejidad.

4) Ante el desprecio de sus cercanos, el que intenta ser sabio termina acompañándose de una erudición que no es valorada y ante tan nefasta soledad solo queda el autoelogio, pues, de cualquier manera, "bien se alaba quien no encuentra otro que lo haga" (2013: 44). El aprendiz de sabio, considerado a sí mismo como sabio consumado, no tendrá otra opción que aislarse de un mundo atestado de locos. Erasmo alude el ejemplo de Timón de Atenas, quien huyó del mundo y solo se relacionaba con Alcibíades, reconocido misántropo de su época en el s. IV a. C. Ante un panorama tan desolador, la ausencia de locura dirige al aislamiento, se debe elegir entre ser 
un insensato adaptado al mundo o un tipo capaz de separarse de la locura para "gozar a solas de su propia sabiduría" (2013: 74).

5) Mientras los deseosos de sabiduría abordan su propia soledad, "la for tuna ama a los insensatos, a los más arriesgados, a hombres que lo «apuestan todo a una carta». La sabiduría, en cambio, hace a los hombres tímidos, y esa es la causa de que con frecuencia los sabios vivan asociados a la pobreza y al hambre, arrinconados, sin fama, mal vistos" (2013: 154). En los negocios ganará quien sabe lanzarse sin pensar en los riesgos o detenerse a analizarlo todo, lo mismo acontecerá con los que buscan convencer o persuadir; las personas no analizan sino que se convencen con la seguridad del oponente, con el carisma de quien se sabe con suerte aun sin contar con certezas de ello. Erasmo asocia, en este punto, la locura con la fortuna, con la riqueza e, incluso, con el aprecio, el bienestar y el confort. Visto así, se entiende que "toda la vida humana, en fin, no es más que una especie de deporte de la insensatez" (2013: 176). Para practicar tal deporte conviene liberarse de los prejuicios y de las ideas de lo que debe ser o de lo preestablecido; esto abrirá las puertas a la vivencia de mayor número de posibilidades y, en ese sentido, favorece la diversidad de experiencias y la intensidad de la existencia. No obstante todas estas ganancias, "pocos son los mortales que se dan cuenta de las ventajas que reporta el verse libre de escrúpulos y estar dispuesto a cualquier aventura" (2013: 78).

6) Otro aspecto esencial de la locura es permitir la ficción, consentirla, difuminarla e, incluso, favorecerla. Comprender que la vida es una especie de actuación reporta como dividendo ser favorecido con los mejores roles, probablemente los protagonistas. Asumirse en una constante actuación implica el reconocimiento de la actuación ajena. En una sociedad de locos no es el fondo lo que atrae sino las formas. No es la sesuda conclusión lo que se contagia sino la energía con lo que algo sea dicho, sin importar si es o no una tontería. Esto es debido a que "la misma ficción y el maquillaje es lo que atrae la mirada de los espectadores" (2013: 79). Por el contrario, los eruditos tratan de desenmascarar, mostrar la falsedad y señalar la fallida actuación de los demás. No se dan cuenta de que con eso no hacen más que seguir, ellos mismos, la actuación de desenmascaradores. 
De tal modo, poco importa la razón en una comunidad de insensatos y estúpidos, pues la razón misma es el instrumento con el que se aniquila el espectáculo; en ese sentido "si alguien intentara quitar la máscara a los actores mientras están en escena, y mostrara a los espectadores su verdadero rostro, ¿no estropearía la función, y se haría por ello acreedor a que lo arrojaran de la sala a pedradas por loco?" (2013: 78-79).

7) La locura pretende, además, no prestar atención a las dificultades de la vida. Es por ello que un hombre prudente, enraizado en su categoría de mortal, se distingue por "no querer una sabiduría superior a su condición humana común” (2013: 80); de tal manera, cualquier pretensión por comprender el mundo, a las personas, la realidad, la ciencia, la naturaleza o a Dios, es sinónimo de sufrimiento y pesar, por no "estar dispuestos a hacer la vista gorda" (2013: 80) ante las cosas que aparentemente no tienen explicación. A la vez, los individuos autocríticos, incapaces de reírse de sus fallas o de "reírse de sus desaciertos con todos los demás” (2013: 80) caen en el error de creer que pueden hacer algo para cambiar o ser mejores, cuando en realidad eso no está en sus manos.

8) Hasta aquí podría pensarse que la locura es solamente cínica y que el mismo Erasmo, él como individuo particular, al no contar con las cualidades propias de la locura era, por tanto, un tipo sensato. Lo mismo pasaría con todos los filósofos, los seguidores congruentes de una religión, o los que estudian para encontrar respuestas, es decir, los investigadores y científicos. No obstante, Erasmo encuentra que en la actitud de alejarse de las reacciones comunes, de las costumbres establecidas y de las tradiciones estipuladas no podría ser simplemente contraria a la Locura, como personaje, puesto que, entonces, estos mismos habrían escapado de ella. Probablemente el punto más fino del elogio erasmiano a la Locura sea que demuestra que incluso los que eligen el camino tortuoso y angosto de la erudición, la independencia o la autenticidad, son también, precisamente, poseídos por la locura. En este caso, naturalmente, no se trata de la misma forma de locura, sino de una locura contraria a la que domina a la muchedumbre: es una locura con un tinte diferente. 
9) De tal modo, la actitud de buscar ser diferente a los locos es también muestra de insensatez. Sin embargo, esta es una insensatez de una categoría peculiar. La mayor locura se presenta cuando se busca la vida mística, la interioridad que permite un encuentro con algo mayor. De acuerdo con Rodríguez, es precisamente en este punto en que "la locura o estulticia puede ser la suprema sabiduría" (2013: 22).

Es en este orden de ideas en el que se presenta el humanismo de Erasmo. El humano se convierte en un individuo capaz de elegir, no entre la cordura o la locura, sino por el tipo de locura que le interesa más: la locura cínica propia del disfrute, la fortuna, la fama, la riqueza, el aplauso y la ficción; o la locura sublime, la que está implícita en el que elige el saber, la elección independiente y la mística, sin desanimarse ante la desdicha, el aislamiento, el desprecio o la soledad. Evidentemente, en ambas circunstancias se cumple lo establecido por la Locura en cuanto que nadie se ve libre de ella.

Es en este panorama en el que Erasmo introduce lo que él consideró la locura de Cristo. El método de perfección de tal locura estaría indicado en el Enchiridion o Manual del caballero cristiano, cuya publicación aconteció en 1526. Erasmo llama «filosofía de Cristo»a "una síntesis de la teología y la espiritualidad, síntesis hecha de conocimiento y de amor, alimentada por la meditación, la oración y el renunciamiento, coronada por la unión con Dios" (Halkin, 2012: 145). Comprender a la locura como aquello que permite a un individuo romper con lo establecido la vuelve, hasta cierto punto, una cualidad digna de elogio. Existe, entonces, un elogio implícito cuando Erasmo aseguraba que los religiosos y los místicos estaban poseídos por la locura. Como podría esperarse, las reacciones más intensas en contra de Erasmo fueron promovidas por algunos miembros de la Iglesia a la que pertenecía. En su defensa, el pensador de Rotterdam aludió en primera persona: "Quise aconsejar, no morder; hacer el bien, no insultar; trabajar, pero no contra los intereses de los hombres" (Erasmo, 2013: 184).

Evidentemente, es digno de consideración que la locura decantada hacia la mística no sea exclusiva del cristianismo y, desde esa óptica, es posible comprender de un modo más general la propuesta de Erasmo para no sujetarla y disminuirla al nivel de un catecismo 
erudito. Autores como Moya (2008) reducen su exposición a una especie de síntesis del pensamiento erasmiano, sin dilucidar que los alcances implícitos en su obra son de mayor longitud que el estimado a lo estrictamente religioso. Para lograr tal distintivo de universalidad, en lo que Erasmo refiere, es menester que se atienda el carácter crítico de su espiritualidad y las nociones de vacuidad implícitas en la Stultitiae Laus; cabe advertir que esta percepción de vacuidad a la que se hace alusión, como se verá más adelante, remite a un estado fecundo y propiciador (bajo ciertas condiciones) de una mística fructífera, muy alejado del devastador nihilismo que intenta sostenerse en sí mismo sin alternativa ni locución.

\section{La ironía de criticar la criticidad}

La espiritualidad que manifiesta Erasmo en sus obras, principalmente en el Elogio a la Locura, está sustentada en un ejercicio de erudición honesto que es consecuente con la crítica al entorno. La ironía se manifiesta en el hecho de que la criticidad que es criticada es, precisamente, la herramienta utilizada. Tal es una de las principales fortalezas de Stultitiae Laus: mantiene una lógica de doble mensaje, en la que la critica que se realiza al ejercicio racional es, al mismo tiempo, una invitación a ese tipo de labor; el juicio de la erudición, adjudicándole la categoría de locura, transmite el mensaje de que es justo tal locura la que debe preferirse a la que evidencian los que se dedican al placer y la diversión, que son la mayoría.

En sintonía con lo referido, podría entenderse el estilo erasmiano, al menos en esta obra, como un auténtico ejercicio de intención paradójica, ${ }^{1}$ la cual incluye el artificio de persuasión a través del cual se invita al oyente (o lector) a aquello que, a la vez, se solicita no hacer. De tal modo, cuando Erasmo, en voz de la locura, advierte que “un hombre es tanto más feliz, cuanto más insensato" (2013: 98), no

1 El término fue acuñado en el siglo XX por el logoterapeuta vienés Viktor Frankl, principalmente en su libro El hombre en busca de sentido (Madrid: Herder, 1999). También fue popularizado mediante la práctica de la Terapia Breve de Milton Erickson. En su intención didáctica, Erasmo es, al menos en la obra que nos ocupa, pionero de esta técnica. 
se está refiriendo a la insensatez propia de la locura cínica, según se estipuló en el apartado anterior, sino a la insensatez del místico que, en su ejercicio complejo de descubrimiento, es capaz de encontrar felicidad donde otros no la intuyen. Naturalmente, este mensaje no es el que está a la superficie, sino que es comprendido cuando asumimos que el entramado de ideas que propone Erasmo posee la virtud de ofrecer un mensaje destinado a ser un fruto del análisis del lector. Solo así se entiende la crítica siguiente de la Locura a uno de los referentes del ejercicio crítico clásico: "lo que nos dejó Séneca, más que un hombre, es una estatua de mármol, totalmente impávida y desprovista de cualquier sentimiento humano" (Erasmo, 2013: 81).

Debe quedar claro que la voz parlante es la de la Locura, que en su arte orador ofrece un mensaje que puede ser descifrado a través de las alternativas implícitas. En tal dualidad de posibilidades, Erasmo manifiesta posturas que son similares, en su sentido paradójico, a las de la espiritualidad oriental; en los círculos zen se dice: "Antes de empezar a practicar, las montañas eran montañas y los ríos eran ríos. Después de practicar, las montañas dejaron de ser montañas y los ríos dejaron de ser ríos. Ahora después de practicar algún tiempo, las montañas vuelven a ser montañas y los ríos vuelven a ser ríos" (Nhat, 2012: 75). Bajo esa óptica, la locura es locura simple cuando no se le entiende; posteriormente uno opta por la erudición y nota que la capacidad de comprensión tiene límites, por lo que se admite la locura de tratar de comprenderlo todo; finalmente, esa actitud ya no es una locura similar a la inicial, sino que se admite y permite sin que la etiqueta con la que sea nombrada se interponga en la voluntad.

La Locura refiere con claridad que "los mortales que se esfuerzan por alcanzar la sabiduría son por lo mismo los más alejados de la felicidad. En realidad son doblemente estúpidos, primero porque ignoran su condición de hombre, y segundo porque quieren emular a los dioses inmortales y, a ejemplo de los gigantes, hacen la guerra a la naturaleza, valiéndose de las armas de la ciencia” (Erasmo, 2013: 91). No obstante, podría esbozarse que habría, en este caso, al menos dos tipos de felicidad: por un lado, la del que no sabe que no sabe y persiste viviendo en la ilusión; por otro, la del que sabe que no sabe y, aun así, es capaz de identificar cierto gozo en el límite de su 
saber, en llegar hasta lo que sus propias capacidades le permiten ante la implícita fantasía consciente, lo cual es distinto a regocijarse en la ignorancia y en la creencia absoluta de la ficción imperante.

Por tal motivo, una vez que se ha reconocido que los buscadores de sabiduría son estúpidos, también se estipula que "nadie puede alcanzar la perfecta sabiduría, la llamada ciudadela de la felicidad, si la Insensatez no le muestra el camino" (2013: 80). En ese sentido, la insensatez, como conducta y protagonista, es el camino idóneo para tal felicidad. Pareciera, en estos dos pasajes, que existe una contradicción, pero eso se diluye cuando comprendemos los dos tipos de locura que se han expuesto y la intención paradójica del autor a través del personaje de la Locura. La misma sabiduría a la que debe llegarse, de la cual Erasmo hace alusión clara en sus textos, permite romper la dualidad y la dicotomía entre la locura y la sabiduría, permitiendo y asumiendo la unión inalterable entre ellas, con el punto de convergencia en la distinción de, precisamente, los tibios.

La sabiduría no es una insensatez rotundamente cínica, sino que es propia de quienes intentan algo distinto. En ello la ironía de la crítica a la criticidad, pues es tal la que separa un tipo de locura y otra, a saber: la locura de dejar de ser críticos en un mundo incongruente y la locura de ser críticos ante un mundo en el que las críticas fundamentadas parecen no importar.

Es claro que la crítica central que Erasmo podía dirigir era a los miembros de su Iglesia, quienes, a la vez, podrían hacer gala de ambos tipos de locura. Concuerdo con Rodríguez (2013: 17) cuando afirma que "la experiencia de una Iglesia y de una sociedad alejada del ideal cristiano hará que Erasmo - de talante pacífico y conciliador-salte a la palestra para arremeter contra papas, obispos, abades y clérigos que desmienten en su persona y en su oficio el nombre y el ideal de cristiano". Existe cierta semejanza entre la actitud denunciante de Erasmo y lo contenido en algunos textos de la mística budista; por ejemplo, en el Prajñaparamita, ${ }^{2}$ los primeros sutras exponen variadas frases que critican y condenan la actitud de los

2 Los sutras del Prajñaparamita pertenecen al budismo Mahayana y abordan la cuestión de la sabiduría y los caminos para lograrla. 
monjes que se olvidan del bien común y se centran exclusivamente en su propio bienestar. Era de esperar que las críticas no fueran bienvenidas y que el mensaje implícito, aunque no expuesto, del texto erasmiano no fuera comprendido. Es por esto que los teólogos de Lovaina y París no perdonaron la sátira de Erasmo. Aun en tales condiciones, el pensador de Rotterdam "rehusó separarse de una Iglesia cuyos abusos denunciaba" (Halkin, 2012: 13).

De acuerdo con Halkin puede pensarse que "no hay en Erasmo más que un humanista cristiano que aborda géneros literarios diferentes, con un éxito debido a su virtuosidad de escritor" (2012: 176), pero también puede verse en él a un pensador que esbozó la propuesta de un cierto vacío necesario para anteceder a la vivencia de una mística sublime. Esta crítica de las formas y los modos fue extendida por Erasmo hacia las vivencias de otras religiones. Es clara su crítica a las peregrinaciones cuando pregunta: “ $¿$ Es importante ir en persona a Jerusalén cuando, en lo íntimo de su alma, el peregrino se queda en Sodoma, en Egipto o en Babilonia?" (1706: V, 38A). También criticó el orgullo y la vanidad en general cuando, en voz de la Locura, cuestiona: “¿Puede haber algo tan necio como gustarse y sentir admiración por uno mismo?” (2013: 68). Se observa que Erasmo promueve la aprobación de la desaprobación, es decir, no sólo el juicio autocrítico sino el reconocimiento de la pequeñez, de la falacia de lo humano en el mundo, de la fluidez con la que se friccionan entre sí, destruyéndose, todas las explicaciones humanas ante lo desconocido.

No solo los religiosos que buscan en sus creencias la consolidación de su ejercicio espiritual están poseídos por la insensatez, sino que también los filósofos, constantes indagadores de la verdad oculta en la paja de la apariencia, degluten su porción diaria de estulticia. Erasmo refiere, a través de la Locura, que los filósofos "no saben nada con certeza, y buena prueba de ello es la interminable contienda entre ellos sobre cualquier tema" (2013: 125). Por eso la búsqueda filosófica es también una especie de insensatez, pero que cubre de distinción a quienes la practican; distinción que, además, no es siempre valorada por el vulgo o la masa de los que abrazan la locura cínica. Por todos estos motivos, "el hombre que tenía como lema el 
Nulli concedo: «no cedo ante nadie», nos dio un ejemplo admirable de humanitas" (Rodríguez, 2013: 18).

La mística de la vacuidad en el paso de lo cínico a lo sublime

La crítica realizada por Erasmo a la espiritualidad convencional de su tiempo nos traslada a un estado de vacío en el que las opciones tradicionales, y las formas de concretarlas, no son suficientes. De esto se deriva la búsqueda de otros modos de proceder para vivenciar la espiritualidad; tal búsqueda está salpicada de insensatez, pero, tal como se ha advertido, esta es una insensatez que está en conexión con una locura sublime en cuanto que admite el dolor, la soledad y el aislamiento a cambio de una felicidad interior que no puede compararse al aplauso, la fama o la riqueza.

El término de "nihilista" podría parecer lejano a Erasmo y no existe intención en estas líneas de catalogarlo como tal; lo que se busca es mostrar que en el proceso hacia una búsqueda individual de las propias respuestas espirituales, camino que él mismo recorrió en compañía de los clásicos, existe un estado de vacuidad necesario y, por tanto, parcialmente nihilista. El miedo al vacío y a su inseparable sensación de desconexión constituye, probablemente, el principal obstáculo para encaminarse a una búsqueda más allá de las formas convencionales, populares o consensuadas. Tampoco se trata de ser antipáticos a la razón, sino de persuadirse de que la razón misma es el preámbulo de un estado espiritual que no es posible sin el paso o el trascurso que ella permite. Implica el reconocimiento del límite de las propias fuerzas, pero este reconocimiento es factible únicamente tras el uso de la razón, no a través de exentarse de su medio. La diferencia entre el fanatismo y la mística es que el primero de ello excluye desde el principio el ejercicio racional y, con distinción de lo segundo, no posibilita la momentánea experiencia de saberse sin respuestas.

La Locura en su elogio, refiere que "la religión cristiana tiene cierto parentesco con la insensatez, sin que tenga nada que ver con 
la sabiduría" (2013: 170). Es claro que Erasmo realiza, en este pasaje, un elogio al cristianismo, suponiéndole capaz de superar el estado racional y asumiéndole con la fuerza de alcanzar una Sabiduría superior a la humanamente posible. Naturalmente, que tal acontecimiento suceda en la vivencia particular de cada cristiano es una cuestión que debe ser sometida a análisis.

No solo en la obra de Erasmo, sino en su vida misma se observa que el estudio es parte de la oración y una forma de consagración a lo absoluto, es decir, aquello que, aun buscándose, nunca se posee por completo. Por tal motivo solía reiterar que la verdadera teología se construye a partir de una exégesis filológica, lo cual requiere del dominio de la antigua literatura profana. Sólo los que tengan cierto conocimiento literario de este tipo serían capaces de entender a Erasmo. En su carta a Dorp mencionó: "Doy más crédito a la opinión de teólogos sabios y eruditos que lejos de acusarme de severo hasta alaban mi sinceridad y el tacto con que he tratado un tema tan vidrioso sin sobrepasarme, divirtiéndome sin malicia en algo tan resbaladizo" (2013: 198). Irónicamente, el valor de la insensatez sublime se evidencia en la búsqueda realizada a través de las letras. En ese sentido, el entusiasmo hacia el conocimiento y el padecimiento de su indagación es por sí mismo un ejercicio místico.

Erasmo era consciente de que la auténtica vivencia espiritual requiere de un ejercicio integral de la persona, el cual debe incluir también el pensamiento racional hasta el punto en que éste sea posible. Por tal motivo aceptó que "parte de nuestro conocimiento estriba en aceptar que hay algunas cosas que no podemos conocer, y otras muchas en que la incertidumbre es más provechosa que la misma certeza" (2013: 2000). Así, en su afán de unir tal convicción con la creencia que le fue inculcada en el grupo al que estuvo vinculado desde su nacimiento, "echando mano de la Biblia trata de probar que el cristianismo -y la bienaventuranza- no son más que locura sublime" (Rodríguez, 2013: 25).

Cuando refiere a la insensatez mística, Erasmo es claro al referir que no se trata de una cuestión cuya extensión abarque unos pocos días, sino que es de toda la vida; concretamente, "es esa parte de 
necedad que no desaparece por el cambio de la vida, sino que se perfecciona. Así pues, los que han podido saborearla de antemano, y han sido muy pocos, experimentan algo que se parece mucho a la locura" (2013: 176). Asimismo, los que viven momentos de despido de la razón, luego que la razón misma no les ha sido suficiente, han entendido un elemento post-racional, que debe pasar por lo racional para elevarse más allá de la razón. Una vez que se llega a tal estado, "solo saben que fueron felicísimos durante este éxtasis. Se lamentan de haber vuelto a la razón, ya que nada desean más que vivir perpetuamente esta clase de locura" (2013: 177).

En tales casos nos referimos, entonces, al tipo de locura que se anhela constantemente, que no se trata solamente de un despido del mundo tras haberlo habitado, ni de un despido de la razón tras haberla utilizado, sino que es el desenlace momentáneo en el que todo es vivido de manera conjunta en armonía mediante la unión de los extremos y la negación de la dualidad, a saber: una separación que une, una distancia que acerca y una elevación que implica haber profundizado. Esta posibilidad, no obstante ser posible para todos, no es explorada ni deseada por la mayoría, lo cual es clara muestra de insensatez. Esto se debe a que "el espíritu del hombre está hecho de tal manera que capta mejor la apariencia que la realidad” (2013: 109).

Para Erasmo no había más ciencia que la teología. Naturalmente, no consideró suficiente la búsqueda voluntariosa, sino que asumió la conciencia del límite de tal búsqueda. Su propuesta espiritual se dirige al tipo de humildad que es fundamental para lograr el desconocimiento de sí, la aceptación de la pequeñez y el reconocimiento de la imposibilidad de acceder a la Verdad, sin que ninguna de estas cuestiones implique dejar de buscarla. Continuar la búsqueda es una resolución insensata que, al menos, difiere un poco de la insensatez que invita a renunciar al ejercicio racional y espiritual. Esto no se reduce a una simple cuestión de autoestima, pues "el amor propio no es más que autolisonja, y si esto se hace con otro se torna adulación" (2013: 107). De lo que se trata es de ser capaz de elegir el tipo de insensatez que conviene a la propia vida y, tras hacerlo, ser lo suficientemente insensato para seguir pensando que ha sido uno solo, en su independencia, rigor y pureza, quien ha elegido. En otro de 
sus libros, Erasmo afirmó que "para rey o para necio se nace” (2008: 147), lo cual no significa que cualquier reinado permanezca libre de la necedad.

Existen indicios de reducción a la vacuidad cuando Erasmo desacredita el modo usual de proceder de la Iglesia; esto lleva al vacío momentáneo, al cual no se debe rehuir, pues tal estado de poco apetito por lo tradicional fructifica en la admisión de un tipo de fe que confía en una respuesta, motivo o sentido superior a lo cognoscible. En este proceso, lo que Erasmo propone es similar a lo que posteriormente estableció Kierkegaard como "estado religioso", al cual se llega solamente tras recorrer (y superar) el estado ético y estético. La locura cínica concuerda con el tipo de vivencias que se experimentan en el estado estético; corresponde al estado religioso cierta similitud con la locura sublime. Precisamente, el punto intermedio entre ambas es el punto de la elección por una de las dos, entendiendo que la ética, justamente, está caracterizada por la capacidad de optar. Para que tal opción sea posible, en un acto en el que las opciones tienen cierta neutralidad inicial, se requiere de un estado de vacuidad del cual puede emerger la elección tras ubicar la conexión, preferencia o predilección, con alguna de las alternativas. Sin embargo, no hay formar de realizar tal ejercicio ético cuando se ha perdido la claridad del derecho a optar, lo cual es propio de la vivencia fanática.

Asimismo, existe un vínculo entre Kierkegaard y Erasmo cuando cada uno plantea los términos de «caballero de la fe» y «caballero cristiano», respectivamente. En similitud con el danés, Erasmo considera que "ha sido siempre costumbre de los sabios confiar al papel sus alegrías y tristezas, como amigo fiel en cuyo pecho se puede vaciar toda la turbulencia del corazón. Se pueden encontrar, en efecto, personas cuya sola intención al escribir un libro es verter todas sus emociones y así trasmitirlas a la posteridad" (2013: 182). En lo que respecta al trabajo de Erasmo, su mensaje y su intención, el presente artículo intenta ser un argumento para evidenciar que tal afirmación corresponde enteramente a su obra.

Erasmo anheló una vida que los "sensatos" califican de locura; por ello que "concibe la realidad en función de sus sueños y se distancia 
críticamente del mundo tal como ha llegado a ser" (Oelker, 2005: 16). Mantuvo firme su idea sobre el valor de la vida y la conclusión de que algo mayor que el hombre sostiene el motivo de la existencia. A pesar de mantener el uso de latín en su vida académica, su última frase la refirió en alemán; de acuerdo con Zweig "Embargado por el miedo primordial de las criaturas de la creación, sus labios entumecidos balbucean el «Amo a Dios» de su niñez en el mismo bajo alemán de entonces, pronuncia las primeras y las últimas palabras de su vida en la misma lengua" (2005: 206). Más allá de la interpretación de Zweig, respecto al miedo que motiva las últimas palabras de Erasmo, cabe establecer la posibilidad de que su ingreso a los brazos de la muerte haya sido antecedido por la conciencia de la inmensidad de una deidad en cuyo regazo solo cabe atestiguar lo absoluto de su vacuidad.

\section{Conclusión}

En Erasmo se encuentra claramente una crítica de un hombre de fe a los miembros de la institución religiosa que amó. Su obra nos persuade de su capacidad de distinguir entre el seguimiento ciego y el señalamiento erudito. La responsabilidad que ejercen las letras en un hombre de letras es proporcional a su ironía y astucia.

A pesar de que su Elogio a la Locura desató terribles críticas en su contra es también una obra que sintetiza gran parte de sus intenciones literarias. Considerando que la locutora de la exclamación del texto es el personaje de la Locura, puede señalarse que la intención erasmiana era elogiar la elección hacia la búsqueda intelectual y la vida mística, a pesar de la insensatez que ambos caminos representan en el contexto de un mundo extasiado por el placer y el bienestar personal. Si bien a esto último cabe ubicarlo también en el parámetro de lo insensato, puede distinguirse que se aludiría a una insensatez cínica, cuya esencia es diferente a la sublime.

El camino de la distinción entre la locura cínica y la sublime está delimitado por la experiencia de la vacuidad que sea vivida. Bajo ese tenor, en la obra de Erasmo existen indicios del punto de vista 
de la vacuidad que es antecedente ineludible para el traslado de una locura cínica a una locura sublime y mística. La incomprensión de esa situación o la nula vivencia del estado de vacuidad que antecede a la mística es lo que lleva a la desaprobación y al descrédito de la obra erasmiana. Está claro que el término de nihilismo es inapropiado para etiquetar el pensamiento de Erasmo; lo que cabe es referir el elemento implícito de la vivencia de la vacuidad, asociada a la insatisfacción, la duda, la crítica y la separación, que está inmersa como condición previa al desarrollo de la espiritualidad crítica que propone el filósofo de Rotterdam. Su espiritualidad encuentra en la criticidad, justamente, su sinergia constante y su renovación.

La locura ofrece posibilidades: hacia el cinismo e insensatez cotidiana o hacia la sublime insensatez de la mística. Está claro que Erasmo, junto con Eckhart o Kierkegaard, ha elegido lo segundo. En las conclusiones del holandés se observan leves esbozos y afinidades con postulados orientales y, tal como sucede con un bodhisattva, intentó llevarlas hasta la última consecuencia. Es por todo esto que puede decirse, sin asomo de duda, tal como hizo Halkin, que "la doctrina de Erasmo es una, como su vida” (2012: 176).

Referencias bibliográficas

Bataillon, M. (1966). Erasmo y España, México: Fondo de Cultura Económica.

De Paz, M., R. Padrón, F. Salas. (2008). "Erasmo en el refectorio. La biblioteca franciscana de Garachico”. En Anuario de Estudios Atlánticos, 2, 54: 85-118.

De Rotterdam, E. (1706). Opera omnia Desiderii Erasmi Roterodami. J. Lecrerc (ed), 10 vols. Leiden: Petrus van der Aa.

. (1958). Opus epistolarum Desiderii Erasmi Roterodami, PS Allen; HA. Allen (eds.), 12 vols. Oxford: Clarendon Press.

. (2008). Los adagios del poder y de la guerra y Teoría del adagio. R. Puig (trad.). Madrid: Alianza.

(2013). Elogio de la locura. P. Rodríguez (trad.). Madrid: Alianza.

Fantazzi, C. (2008). "Prefacio". En Erasmo, Adagios del poder y de la guerra y Teoría del adagio: 11-13. Madrid: Alianza. 
Halkin, L. (2012). Erasmo. México: Fondo de Cultura Económica.

Moya, J. (2008). “En torno de Desiderio Erasmo y de Laus Stultitiate”. Praxis, 5, 62, 192-227.

Nhat, T. (2012). La esencia del amor. Barcelona: Oniro.

Oelker, D. (2005). "La locura nace en las islas afortunadas". En Atenea, 492: 11-30.

Perez, J. (2015). “Erasmo, Moro y Vives”. Revista eHumanista, 5, 29: 1-12.

Rodríguez, P. (2013). “Introducción”. En E. De Rotterdam. Elogio de la locura: 9-32. Madrid: Alianza.

Zweig, S. (2005). Erasmo de Rotterdam. Triunfo y tragedia de un humanista. Barcelona: Península. 